\title{
OPTIMIZATION AND MODELING OF FLOW CHARACTERISTICS OF LOW-OIL DDGS USING REGRESSION TECHNIQUES
}

\author{
R. Bhadra, R. P. K. Ambrose, M. E. Casada, S. Simsek, K. Siliveru
}

\begin{abstract}
Storage conditions, such as temperature, relative humidity (RH), consolidation pressure (CP), and time, affect the flow behavior of bulk solids such as distillers dried grains with solubles (DDGS), which is widely used as animal feed by the U.S. cattle and swine industries. The typical dry-grind DDGS production process in most corn ethanol plants has been adapted to facilitate oil extraction from DDGS for increased profits, resulting in production of low-oil DDGS. Many studies have shown that caking, and thus flow, of regular DDGS is an issue during handling and transportation. This study measured the dynamic flow properties of low-oil DDGS. Flow properties such as stability index (SI), basic flow energy $(B F E)$, flow rate index (FRI), cohesion, Jenike flow index, and wall friction angle were measured at varying temperature $\left(20^{\circ} \mathrm{C}, 40^{\circ} \mathrm{C}, 60^{\circ} \mathrm{C}\right), \mathrm{RH}(40 \%, 60 \%, 80 \%)$, moisture content (MC; $8 \%, 10 \%, 12 \%$ w.b.), CP (generated by 0,10 , and $20 \mathrm{~kg}$ overbearing loads), and consolidation time (CT; 2, 4, 6, 8 days) for low-oil DDGS. Response surface modeling (RSM) and multivariate analysis showed that $M C$, temperature, and $R H$ were the most influential variables on flow properties. The dynamic flow properties as influenced by environmental conditions were modeled using the RSM technique. Partial least squares regression yielded models with $R^{2}$ values greater than 0.80 for SI, BFE, and cohesion as a function of MC, temperature, RH, CP, and CT using two principal components. These results provide critical information for quantifying and predicting the flow behavior of low-oil DDGS during commercial handling and transportation.
\end{abstract}

Keywords. Dynamic flow properties, Flowabilty, Low-oil DDGS, Multivariate modeling.

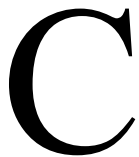

haracterizing bulk granular flow properties is important because physical (compaction) and environmental (temperature and relative humidity, $\mathrm{RH})$ variations affect bulk properties during storage, transportation, and mixing (Knowlton et al., 1994). Distillers dried grain with solubles (DDGS), a coproduct from the corn-based ethanol industry, is a bulk granular commodity that is handled and transported at commercial scale in the U.S. Because of its protein content (nearly $30 \%$ dry basis, d.b.) and other key nutrients essential for animal growth, DDGS has been used extensively as animal feed for rumi-

Submitted for review in May 2016 as manuscript number PRS 11928; approved for publication by the Processing Systems Community of ASABE in November 2016.

This research was supported by USDA (CRIS No. 5430-43440-00800D) and the Andersons Research Grant Program, Team Competition. Mention of trade names or commercial products in this article is solely for the purpose of providing specific information and does not imply recommendation or endorsement by the USDA. The USDA is an equal opportunity provider and employer.

The authors are Rumela Bhadra, ASABE Member, Research Associate, Department of Biological and Agricultural Engineering, Kansas State University, Manhattan, Kansas; R. P. Kingsly Ambrose, ASABE Member, Assistant Professor, Department of Agricultural and Biological Engineering, Purdue University, West Lafayette, Indiana; Mark E. Casada, ASABE Member, Research Agricultural Engineer, USDA-ARS Center for Grain and Animal Health Research, Manhattan, Kansas; Senay Simsek, ASABE Member, Professor, Department of Plant Sciences, North Dakota State University, Fargo, North Dakota; Kaliramesh Siliveru, ASABE Member, Graduate Research Assistant, Department of Grain Science and Industry, Kansas State University, Manhattan, Kansas. Corresponding author: R. P. Kingsly Ambrose, 225 S. University St., Purdue University, West Lafayette, IN 47907; phone: 765-494-6599; e-mail: rambrose@purdue.edu. nants and non-ruminants (Spiehs et al., 2002). Due to this high demand as animal feed, DDGS adds to the overall profitability of the corn ethanol industry.

The typical dry-grind corn to ethanol conversion process results in DDGS with fat content ranging from about $8 \%$ to $12 \%$ (d.b.). However, in the last decade, extraction of oil (corn oil) from DDGS has become lucrative for creating additional profits without compromising the nutritional quality of DDGS. More than $50 \%$ of the operating dry-grind ethanol plants extract oil from DDGS (Shurson and Kerr, 2012). At present, in the dry-grind processing plants, corn oil is extracted from the thin stillage stream (with a potential of removing approximately $30 \%$ of corn oil) or after condensed distillers solubles (CDS) is mixed with wet cake. Most of the plants use a combination of the above methods to extract approximately $65 \%$ to $70 \%$ of corn oil. This is also known as the "back-end" extraction method (Shurson and Kerr, 2012). The fat content in low-oil DDGS ranges from approximately $4 \%$ to $6 \%$ (d.b.) with these extraction processes. Currently, corn oil is sold at $\$ 0.90 \mathrm{~kg}^{-1}$ for primary use in the biodiesel industry, thereby stimulating use of back-end extraction in the dry-grind ethanol process in order to produce low-oil DDGS (Jessen, 2013).

Caking and cohesiveness among the particles in a bulk state are the primary disadvantages of DDGS during handling and transportation. Environmental and storage conditions may exacerbate the caking phenomenon in DDGS. Storage and transportation at high RH conditions and in low and high temperature environments could lead to particle caking due to moisture migration and formation of solid bridges. In addition to temperature and $\mathrm{RH}$, consolidation 
pressure $(\mathrm{CP})$ and consolidation time $(\mathrm{CT})$ could also significantly affect the bulk behavior of granular solids. McNeill et al. (2008) measured changes in bulk density due to overbearing pressures from 0 to $69 \mathrm{kPa}$ for five feed ingredients (cracked corn, corn meal, soybean meal, cotton seed meal, and distillers dried grain without solubles). They found that distillers grains exhibited the highest level of packing among these five ingredients and that packing increased with increasing moisture content. Teunou and Fitzpatrick (2000) found that tea and whey permeate powders showed higher powder cohesiveness when CT was increased.

Ganesan et al. (2009) reported that reduced-fat DDGS ( $2.1 \%$ d.b.) had a slightly better flow behavior compared to regular (9.3\% d.b.) DDGS. However, they classified both the reduced-fat and regular DDGS as "cohesive" powders. Many studies have quantified the flow challenges in regular DDGS (Ganesan et al., 2007; Bhadra et al., 2013) and explained how changing process conditions and storage scenarios could influence flow problems in regular DDGS, but no studies have quantified the flow problems of low-oil DDGS and their correlation with environmental and storage conditions.

The objectives of this research were:

- To measure the dynamic flow properties of low-oil DDGS as influenced by moisture content (\% w.b.), storage temperature $\left({ }^{\circ} \mathrm{C}\right)$, relative humidity $(\%)$, consolidation pressure $(\mathrm{kPa})$, and consolidation time (days).

- To develop response surface models to predict and characterize the flow properties of low-oil DDGS as a function of storage and consolidation variables.

- To characterize the flow properties of low-oil DDGS using multivariate component analysis and model the flow properties of DDGS using partial least squares (PLS) regression technique.

\section{MATERIALS AND METHODS}

\section{SAMPLE COLLECTION AND EXPERIMENTAL DESIGN}

Samples of low-oil DDGS were collected from a commercial ethanol plant (from one batch) and stored at $5^{\circ} \mathrm{C}$ until the experiments. We assumed that the difference in lowoil DDGS compositional quality between processing batches is negligible. The average fat content of the low-oil DDGS was found to be $5.36 \%$ (d.b.). Particle size and particle size distribution of the samples, before conditioning, were determined using a Rotap sieve analyzer (model RX-29, Tyler Manufacturing, Mentor, Ohio). The geometric mean diameter (GMD) and geometric standard deviation (GSD) were calculated using ASAE Standard S319.4 (ASABE, 2009). Bulk density of low-oil DDGS was measured using a standard Winchester cup (Seedburo Equipment, Chicago, Ill.) setup, and true density was determined using a gas multipycnometer (AccuPyc II 340, Micromeritics, Norcross, Ga.). Angle of repose was measured according to ASTM standard method D6393 (ASTM, 1999) for Carr (1965) indices using a powder characteristic tester (model PTR, Hosokawa Micron Powder Systems, Summit, N.J.). Physical property measurements were made in triplicate.
Table 1. Low-oil DDGS sample conditioning methods.

\begin{tabular}{cccc}
\hline $\begin{array}{c}\text { Moisture } \\
\text { Content } \\
(\% \text { w.b. })\end{array}$ & $\begin{array}{c}\text { Temperature } \\
\text { and Relative } \\
\text { Humidity }\end{array}$ & $\begin{array}{c}\text { Consolidation } \\
\text { Pressure } \\
(\mathrm{kPa})\end{array}$ & $\begin{array}{c}\text { Consolidation } \\
\text { Time } \\
(\text { days })\end{array}$ \\
\hline $8,10,12$ & $20^{\circ} \mathrm{C}$ at $40 \% \mathrm{RH}$, & $0,3.44,6.89$ & $2,4,6,8$ \\
& $40^{\circ} \mathrm{C}$ at $60 \% \mathrm{RH}$, \\
& $60^{\circ} \mathrm{C}$ at $80 \% \mathrm{RH}$ & & \\
\hline
\end{tabular}

The dynamic flow properties of DDGS were measured at different moisture, humidity, and consolidation conditions, as listed in table 1. Distilled water was added to the samples, which were then mixed for $30 \mathrm{~min}$ in a sample mixer for uniform distribution of moisture. After mixing, the samples were stored at $5^{\circ} \mathrm{C}$ for $72 \mathrm{~h}$ before the tests. The moisture content was increased to a higher level, and then the samples were spread out on a flat tray for drying to $8 \%, 10 \%$, and $12 \%$ (w.b.). For RH, temperature, CP, and CT conditioning, PVC columns ( $0.1905 \mathrm{~m}$ internal diameter, $0.3048 \mathrm{~m}$ height) were used. The PVC columns with samples were conditioned in an environmental chamber, and fresh samples were used for each conditioning method.

Zero consolidation pressure reflected no weights on the DDGS samples, but 10 and $20 \mathrm{~kg}$ consolidation weights were used on DDGS samples for 3.44 and $6.89 \mathrm{kPa}$, respectively. Pressure from known consolidation weights was calculated using the exposed surface area of low-oil DDGS inside the PVC columns. Because transportation of DDGS from the Midwest region of the U.S. to the coasts for international shipping takes one to two weeks, we used CTs of approximately one week and simulated overbearing pressure values in an industrial-scale DDGS pile. Temperature and humidity ranges were selected in order to simulate spring and summer conditions in the Midwestern U.S. (mostly ranging from $0^{\circ} \mathrm{C}$ to $40^{\circ} \mathrm{C}$ ), and we added an extreme high temperature condition of $60^{\circ} \mathrm{C}$ for comparison. In summary, the full factorial design was comprised of three moisture levels, three RH and temperature combinations, three CP levels, and four CTs $(3 \times 3 \times 3 \times 4=108$ treatment combinations trials). Each treatment was made in triplicate, with a total of 324 trials to measure the flow properties.

\section{Dynamic Flow Property Measurement}

The dynamic flow behavior of low-oil DDGS was measured using an FT4 powder rheometer (Freeman Technology, Tewkesbury, U.K.) that quantifies the flow properties of powders in terms of the energy required to make them flow. The FT4 powder rheometer system consists of a vertical glass sample container $(120 \mathrm{~mm}$ height, $50 \mathrm{~mm}$ internal diameter) and a rotating blade $(48 \mathrm{~mm}$ diameter, $10 \mathrm{~mm}$ height), which navigates through the sample up and down, and either in clockwise or anti-clockwise direction. The FT4 calculates the flow properties by continuously measuring the forces causing deformation and flow of the powder imposed by the moving blade (Leturia et al., 2014; Bian et al., 2015). The flow properties described below were evaluated using the FT4:

Basic flowability energy (BFE): The energy required to establish a specific flow pattern for a precise volume of particulate solid materials is called the basic flowability energy (BFE). It is a tool to measure the effect of moisture and agglomeration on solid material flow. BFE is calculated from 
the work done in moving the blade at $100 \mathrm{~mm} \mathrm{~s}^{-1}$ tip speed during downward movement through the samples.

Stability index (SI): The stability test is a combination of repetitive conditioning and test cycles of identical parameters, designed to assess if the powder is going to change its form (agglomerate, segregate, or break) as a result of being made to flow. This test does not involve using an external variable, such as flow rate or air velocity. Hence, any change in the flow energy is directly related to the change in powder flow properties. The stability test program includes seven test cycles. Stable samples result in similar measurements during the cycle of measurements. For stability measurement, all test cycles were conducted at $100 \mathrm{~mm} \mathrm{~s}^{-1}$ blade tip speed with the blade moving transversely down the vessel. The stability index (SI) was calculated using the following relationship:

$$
\mathrm{SI}=\left(\frac{\text { Total energy consumed at test } 7(\mathrm{~mJ})}{\text { Total energy consumed at test } 1(\mathrm{~mJ})}\right)
$$

An SI value of about 1 indicates a robust powder that is not affected by being made to flow; SI $>1$ indicates a change in powder characteristics due to agglomeration, segregation, and moisture uptake; and $\mathrm{SI}<1$ indicates a change in powder characteristics due to attrition and de-agglomeration (Freeman, 2011).

Flow rate index (FRI): During handling, bulk particulate materials are sensitive to changes in flow rate. Characterizing the flow rate of powders can help improve the process of conveying powders during handling and processing. To assess the flow rate, the flow energy of low-oil DDGS was measured at four different blade tip speeds during downward movement of the blade. The program begins by subjecting the powder to a standard flow rate of $100 \mathrm{~mm} \mathrm{~s}^{-1}$ (test 1), followed by measuring at $70 \mathrm{~mm} \mathrm{~s}^{-1}$ (test 2), $40 \mathrm{~mm} \mathrm{~s}^{-1}$ (test 3 ), and $10 \mathrm{~mm} \mathrm{~s}^{-1}$ (test 4) blade speeds. From the flow energy, the flow rate index (FRI) was calculated using the following relationship (Freeman, 2007a):

$$
\mathrm{FRI}=\left(\frac{\text { Flow energy at test } 4}{\text { Flow energy at test } 1}\right)
$$

The powder characterization based on FRI values is as follows: FRI $>3$ indicates high flow rate sensitivity (very cohesive powder), $1.5<$ FRI $<3.0$ indicates average flow rate sensitivity (most powders fall in this range), FRI $\approx 1$ indicates flow rate insensitivity (powders with large particle size), and FRI $<1.0$ indicates pseudoplastic or Newtonian flow rate (powders containing flow enhancers) (Freeman, 2007b).

Specific energy (SE): The SE value is obtained during upward movement of the blade through the powder. The SE is more dependent on the cohesiveness and mechanical interlocking forces between particles. A measured SE value of $<5$ indicates low cohesion, 5 to 10 indicates moderate cohesion, and $>5$ indicates high cohesion in powders (Freeman, 2008). The SE is calculated from the flow energy using the following relationship:

$$
\mathrm{SE}=\left(\frac{\text { up energy cycle } 6+\text { up energy } 7}{2 \times \text { split mass }}\right)
$$

Shear tests: To understand the condition at which low-oil DDGS initiates flow, the shear properties (cohesion and Jenike flow index, $f f_{c}$ ) were measured under consolidation. Mohr circle analysis was applied to the relationship between the normal and shear stress (yield loci) to calculate the shear properties (Leturia et al., 2014). Shear tests were conducted using an FT4 shear head that induced both vertical and rotational stresses. The normal stress was maintained constant throughout the measurements.

Wall friction angle: This property measures the ability of powders, previously at rest, to flow in relation to the container wall material. In this study, wall friction of low-oil DDGS was measured against stainless steel. A wall friction head attached to the FT4 powder rheometer imposed vertical and rotational stresses on the samples. As the powder bed resisted the rotation of the wall friction head, the torque increased until the resistance was eventually overcome. The wall friction head continued to rotate at a fixed velocity for a predetermined period of time, depending on the powder material and shear level. This usually lasted for several minutes, typically 15 to $45 \mathrm{~min}$. The torque required to maintain this rotational momentum was measured as the shear stress. From the relationship between normal stress $\left(\sigma_{w}\right)$ and shear stress $\left(\tau_{w}\right)$, the wall friction angle $(\phi)$, was calculated using the following relationship (Leturia et al., 2014):

$$
\phi=\tan ^{-1}\left(\frac{\tau_{w}}{\sigma_{w}}\right)
$$

\section{Statistical Analyses}

Statistical analysis, including least significant difference (LSD) testing at $95 \%$ confidence level (i.e., $\alpha=0.05$ ) to determine significant differences between levels of independent variables (main effects) and interaction effects, was done with SAS (ver. 9.1, SAS Institute, Inc., Cary, N.C.). Response surface modeling (RSM) to develop nonlinear regression models for flow properties as a function of independent variables was done with CurveExpert (Professional version 2.0.3, CurveExpert, Madison, Ala.). Multivariate statistical analyses procedures such as principal component analysis (PCA), factor analysis (FA), cluster analysis (CA), and partial least squares (PLS) regression were performed using Minitab (ver. 16, Minitab, State College, Pa.).

\section{RESUlTS AND DISCUSSION \\ Physical Properties of Low-OIL DDGS}

The moisture content of the low-oil DDGS (as received) was $11.56 \%(\mathrm{SD}=0.08 \%)$ w.b. The other physical properties are presented in table 2. The particle size of low-oil DDGS was lower than that of the regular DDGS samples reported by Kingsly et al. (2010). The particle size distribution of low-oil DDGS was narrow (fig. 1): up to about $30 \%$ of samples were retained on the smaller sieve sizes (100 to 840 $\mu \mathrm{m}$ ), and less than $5 \%$ of samples were retained on sieve 
Table 2. Physical properties of low-oil DDGS.

\begin{tabular}{cc}
\hline Parameter & Value $^{[\mathrm{a}]}$ \\
\hline Geometric mean diameter $\left(d_{g w}, \mathrm{~mm}\right)$ & $0.36(0.23)$ \\
Geometric standard deviation $(-)$ & $0.23(0.01)$ \\
Bulk density $\left(\mathrm{kg} \mathrm{m}^{-3}\right)$ & $488.30(1.41)$ \\
True density $\left(\mathrm{kg} \mathrm{m}^{-3}\right)$ & $1353.30(0.00)$ \\
Porosity $(\%)$ & $63.92(0.01)$ \\
Angle of repose $\left(^{\circ}\right)$ & $49.17(0.67)$ \\
\hline
\end{tabular}

[a] Values in parentheses are standard deviations.

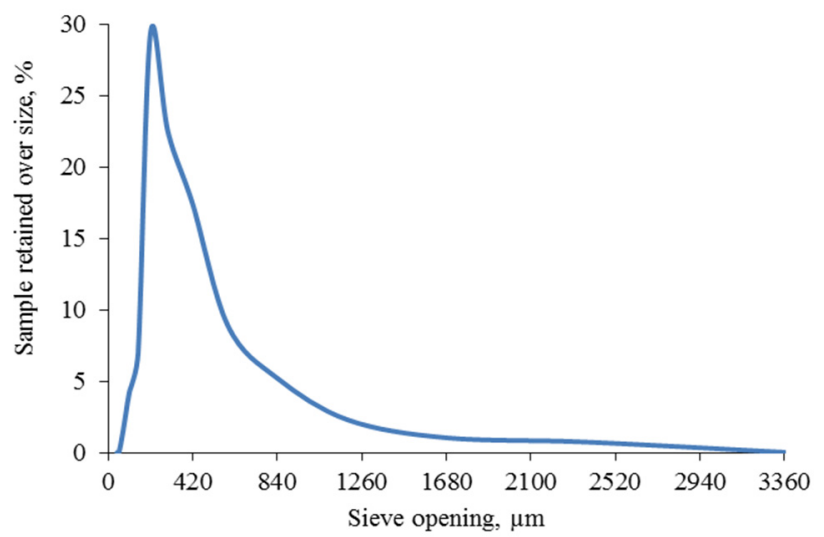

Figure 1. Particle size distribution of low-oil DDGS samples.

sizes larger than $840 \mu \mathrm{m}$. The narrow particle size distribution of low-oil DDGS could result in less segregation during handling than with regular DDGS samples. The bulk and true densities of low-oil DDGS (table 2) were higher than the published values for regular DDGS (Kingsly et al., 2010). In terms of storage vessel design, low-oil DDGS would require less space compared with regular DDGS, which translates into lower cost to hold the same mass compared with regular DDGS. Based on Carr's (1965) classification of powder flow based on the angle of repose, low-oil DDGS could be classified as a powder with poor flowability $\left(46^{\circ}\right.$ to $\left.55^{\circ}\right)$ because the average angle of repose was found to be $49.17^{\circ}$. Typically, a small GMD of bulk material results in a higher angle of repose, indicating greater potential flow problems. The GMD of low-oil DDGS that was used in this study (table 2) is almost half the GMD of regular DDGS reported in the literature. Poor flowability indicates that when low-oil DDGS is loaded in industrial-scale hoppers, arching, rat-holing, and cohesiveness of the particles will be present. This will lead to loss of product during shipping and possibly safety concerns for the workers at the plant (Jenike, 1964; Bhadra, 2009).

\section{MAIN AND INTERACTION EFFECTS ON FLOW Properties OF LOW-OIL DDGS}

Table 3 summarizes the main effect analysis on the independent variables for all flow properties of low-oil DDGS samples measured using the FT4 powder rheometer. Low BFE values indicate better flow for bulk solids (Bian et al., 2015), and the BFE of low-oil DDGS at 8\% $\mathrm{MC}$ was significantly lower $(709.51 \mathrm{~mJ})$ than the samples at $12 \% \mathrm{MC}(721.19 \mathrm{~mJ})$. As expected, at low moisture content, the low BFE value indicates that less energy is required to displace or move low-oil DDGS powders. FRI above 3.0 indicates cohesive tendencies in powders, and values between 1.5 and 3.0 indicate average flow in powders (Freeman, 2007a). The FRI was 4.1 for $12 \%$ MC samples. Furthermore, table 3 shows that high levels of RH, temperature, and CT yielded FRIs greater than 3.0, suggesting cohesiveness of low-oil DDGS samples. These values indicate the potential for particle caking and arching when loaded in industrial-scale hoppers during storage and transport of low-oil DDGS at varying environmental conditions. Similarly, the SE values $(5<\mathrm{SE}<10)$ also indicate that increase in moisture content increases the interparticle cohesion of low-oil DDGS and may affect the bulk flow of DDGS. Moisture content had a significant effect on the SI of low-oil DDGS samples. The increasing trend of SI with

Table 3. Main effects of flow properties due to temperature, RH, moisture content, consolidation pressure, and consolidation time for low-oil DDGS samples. ${ }^{[a]}$

\begin{tabular}{|c|c|c|c|c|c|c|c|c|}
\hline $\begin{array}{c}\text { Independent } \\
\text { Variables }\end{array}$ & Value & $\begin{array}{l}\text { SI } \\
(-)\end{array}$ & $\begin{array}{l}\mathrm{BFE} \\
(\mathrm{mJ})\end{array}$ & $\begin{array}{c}\text { FRI } \\
(-)\end{array}$ & $\begin{array}{c}\mathrm{SE} \\
(\mathrm{mJ})\end{array}$ & $\begin{array}{c}\text { Cohesion } \\
(-)\end{array}$ & $\begin{array}{l}\text { Jenike Flow } \\
\text { Index }\left(f f_{c},-\right)\end{array}$ & $\begin{array}{c}\text { Wall Friction } \\
\text { Angle }\left({ }^{\circ}\right)\end{array}$ \\
\hline \multirow{4}{*}{$\begin{array}{l}\text { Moisture content } \\
\text { (\% w.b.) }\end{array}$} & 8 & $1.29 \mathrm{c}$ & $709.51 \mathrm{c}$ & $2.01 \mathrm{c}$ & $5.28 \mathrm{~b}$ & $0.41 \mathrm{c}$ & $5.80 \mathrm{a}$ & $27.69 \mathrm{c}$ \\
\hline & 10 & $1.31 \mathrm{~b}$ & $715.48 b$ & $3.02 \mathrm{~b}$ & $5.37 \mathrm{~b}$ & $0.62 \mathrm{~b}$ & $5.16 \mathrm{~b}$ & $28.49 \mathrm{a}$ \\
\hline & 12 & $1.35 \mathrm{a}$ & $721.19 \mathrm{a}$ & $4.10 \mathrm{a}$ & $5.76 \mathrm{a}$ & $0.85 \mathrm{a}$ & $3.64 \mathrm{c}$ & $28.13 \mathrm{~b}$ \\
\hline & SD & 0.01 & 1.05 & 0.09 & 0.21 & 0.03 & 0.52 & 1.14 \\
\hline \multirow{4}{*}{$\begin{array}{l}\text { Relative humidity } \\
\text { (\%) }\end{array}$} & 40 & $1.31 \mathrm{a}$ & $715.24 \mathrm{ab}$ & $2.28 \mathrm{c}$ & $5.43 \mathrm{a}$ & $0.61 \mathrm{~b}$ & $5.10 \mathrm{a}$ & $28.46 \mathrm{a}$ \\
\hline & 60 & $1.31 \mathrm{a}$ & $715.35 \mathrm{a}$ & $3.34 \mathrm{~b}$ & $5.48 \mathrm{a}$ & $0.61 \mathrm{~b}$ & $4.87 \mathrm{~b}$ & $28.24 \mathrm{a}$ \\
\hline & 80 & $1.31 \mathrm{a}$ & $715.50 \mathrm{a}$ & $4.01 \mathrm{a}$ & $5.44 \mathrm{a}$ & $0.62 \mathrm{a}$ & $4.77 \mathrm{~b}$ & $28.10 \mathrm{a}$ \\
\hline & SD & 0.01 & 1.19 & 0.09 & 0.18 & 0.03 & 0.41 & 1.10 \\
\hline \multirow{4}{*}{$\begin{array}{c}\text { Temperature } \\
\left({ }^{\circ} \mathrm{C}\right)\end{array}$} & 20 & $1.31 \mathrm{a}$ & $715.25 \mathrm{a}$ & $2.68 \mathrm{~b}$ & $5.43 \mathrm{ab}$ & $0.51 \mathrm{c}$ & $5.21 \mathrm{a}$ & $28.45 \mathrm{a}$ \\
\hline & 40 & $1.31 \mathrm{a}$ & $715.39 \mathrm{a}$ & $3.29 \mathrm{~b}$ & $5.43 \mathrm{a}$ & $0.65 \mathrm{~b}$ & $4.87 \mathrm{~b}$ & $28.03 \mathrm{a}$ \\
\hline & 60 & $1.32 \mathrm{~b}$ & $715.47 \mathrm{a}$ & $4.16 \mathrm{a}$ & $5.48 \mathrm{a}$ & $0.70 \mathrm{a}$ & $4.72 \mathrm{c}$ & $28.09 \mathrm{a}$ \\
\hline & SD & 0.00 & 1.18 & 0.00 & 0.22 & 0.03 & 0.51 & 1.13 \\
\hline \multirow{4}{*}{$\begin{array}{l}\text { Consolidation } \\
\text { pressure } \\
(\mathrm{kPa})\end{array}$} & 0 & $1.30 \mathrm{a}$ & $714.95 \mathrm{~b}$ & $2.01 \mathrm{~b}$ & $5.38 \mathrm{~b}$ & $0.60 \mathrm{a}$ & $4.88 \mathrm{a}$ & $28.06 \mathrm{~b}$ \\
\hline & 10 & $1.31 \mathrm{a}$ & $715.20 \mathrm{~b}$ & $2.11 \mathrm{~b}$ & $5.42 \mathrm{~b}$ & $0.61 \mathrm{a}$ & $4.92 \mathrm{a}$ & $28.45 \mathrm{a}$ \\
\hline & 20 & $1.31 \mathrm{a}$ & $715.96 \mathrm{ab}$ & $3.35 \mathrm{a}$ & $5.61 \mathrm{a}$ & $0.63 \mathrm{a}$ & $4.90 \mathrm{a}$ & $27.81 \mathrm{~b}$ \\
\hline & SD & 0.00 & 1.20 & 0.05 & 0.22 & 0.03 & 0.47 & 0.21 \\
\hline \multirow{5}{*}{$\begin{array}{c}\text { Consolidation } \\
\text { time } \\
\text { (days) }\end{array}$} & 2 & $1.31 \mathrm{a}$ & $714.92 \mathrm{a}$ & $2.01 \mathrm{c}$ & $5.32 \mathrm{c}$ & $0.60 \mathrm{~b}$ & $4.95 \mathrm{a}$ & $28.36 \mathrm{a}$ \\
\hline & 4 & $1.31 \mathrm{~b}$ & $714.85 \mathrm{a}$ & $2.02 \mathrm{c}$ & $5.37 \mathrm{cb}$ & $0.60 \mathrm{~b}$ & $4.92 \mathrm{a}$ & $28.17 \mathrm{ab}$ \\
\hline & 6 & $1.31 \mathrm{~b}$ & $715.19 \mathrm{a}$ & $3.57 \mathrm{~b}$ & $5.42 \mathrm{~b}$ & $0.60 \mathrm{~b}$ & $4.89 \mathrm{a}$ & $27.81 \mathrm{~b}$ \\
\hline & 8 & $1.32 \mathrm{a}$ & $716.51 \mathrm{a}$ & $4.21 \mathrm{a}$ & $5.72 \mathrm{a}$ & $0.64 \mathrm{a}$ & $4.73 \mathrm{~b}$ & $27.96 \mathrm{~b}$ \\
\hline & SD & 0.00 & 1.13 & 0.09 & 0.22 & 0.03 & 0.47 & 1.10 \\
\hline
\end{tabular}

[a] Values followed by the same letter are not significantly different among levels for independent variables for a particular flow property; SI = stability index, $\mathrm{BFE}=$ basic flowability energy, $\mathrm{FRI}=$ flow rate index, $\mathrm{SE}=$ specific energy, and $\mathrm{SD}=$ standard deviation. 
moisture content $(\mathrm{SI}>1)$ could be due to the agglomeration of low-oil DDGS particles at higher moisture levels and could have an influence on the flow pattern during bulk handling.

Jenike flow index $\left(f f_{c}\right)$ values, defined as the ratio of major consolidation stress to unconfined yield strength, were obtained from the Mohr circle plot of failure under varying stress levels. Values between 2 and 4 in Jenike flow index $\left(f f_{c}\right)$ classification indicate "cohesive" powders, and values between 4 and 10 indicate "intermittent flow" powders (Jenike, 1964). For all storage and consolidation variables, the $f f_{c}$ was approximately between 4 to 5 , indicating "intermittent flow" behavior. However, the moisture level of $12 \%$ (w.b.) showed a low $f_{c}$ value of 3.64, strongly suggesting cohesive flow characteristics at high moisture levels. Thus, this is indicative that moisture content plays a major role in determining caking and possible arching problems in lowoil DDGS samples when discharged from industrial-scale hoppers. Although a significant decrease in wall friction angle was measured between a CT of 6 days $\left(27.81^{\circ}\right)$ and 8 days $\left(27.96^{\circ}\right)$, the magnitude of the differences were small. The average wall friction angle for low-oil DDGS was approximately $28^{\circ}$. Particulate material with higher wall friction angles would require a steeper conical hopper section to achieve mass flow from bins. However, in this study, within the range of parameters tested, there was no definite trend in the measured wall friction angle. Furthermore, with smaller differences in the magnitude of measured values, the parameter range tested in this research would not affect the design of hoppers for low-oil DDGS.

For CP as the independent variable, SI, cohesion, and $f f_{c}$ did not show significant differences among levels, as indicated in table 3 . The CT also showed no significant difference among levels for BFE, and RH showed non-significant differences among levels for SI and wall friction angle properties. These differences suggest that, based on the levels selected in this study, variability in flow properties was more likely for independent variables such as moisture content, temperature, and $\mathrm{RH}$ rather than $\mathrm{CP}$ and $\mathrm{CT}$.

Interaction effects of various conditions on flow characteristics of low-oil DDGS are given in table 4. For convenience, only the interaction effects that had a significant effect on at least one flow characteristics are listed. Significant interaction effects $(\mathrm{p}<0.05)$ were observed among the independent variables (moisture content, temperature, $\mathrm{RH}, \mathrm{CP}$, and CT). Overall, interaction effects indicate that these independent variables synergistically affect the properties that influence flow behavior. Most importantly, the combined interaction of moisture content, relative humidity, CT, and CP showed significant effects on most of the dynamic flow properties of low-oil DDGS samples. This indicates that a combination of these effects will affect the handling and transportation of low-oil DDGS.

\section{RESPONSE SURFACE MODELING (RSM) OF FLOW PROPERTIES OF LOW-OIL DDGS}

Based on the results of interaction effects and main effects, response surface modeling was conducted for flow properties as a function of the independent variables for lowoil DDGS samples. As indicated in the previous section (table 3), there was no clear correlation between BFE with $\mathrm{CP}$ and $\mathrm{CT}$, indicating that they are not essential independent variables required to predict BFE. Similar results were observed for flow properties such as SE, SI, FRE, cohesion, $f f_{c}$, and wall friction angle. The results for interaction effects and main effects indicated that most of the flow properties were

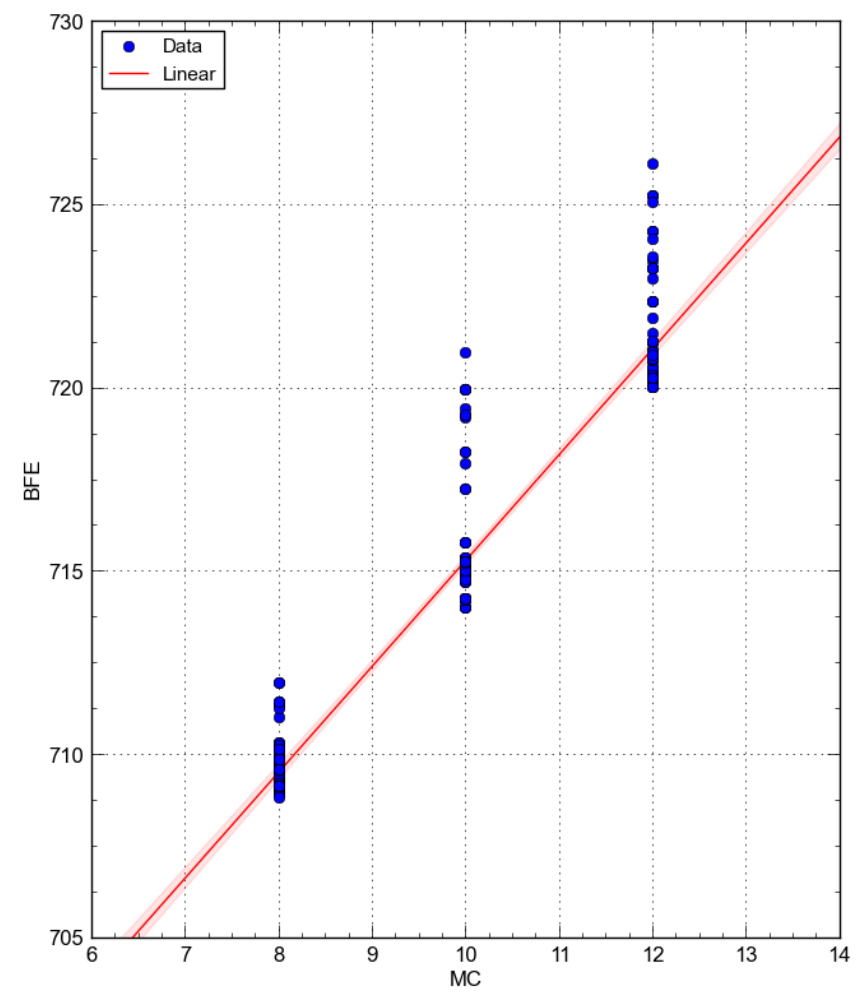

Figure 2. Effect of moisture content on basic flowability energy (BFE) of low-oil DDGS at $95 \%$ confidence levels.

Table 4. Interaction effects (p values) due to external variables on the flow properties of low-oil DDGS. ${ }^{\text {[a] }}$

\begin{tabular}{|c|c|c|c|c|c|c|c|}
\hline Interaction $^{[\mathrm{b}]}$ & $\begin{array}{l}\text { SI } \\
(-)\end{array}$ & $\begin{array}{l}\mathrm{BFE} \\
(\mathrm{mJ})\end{array}$ & $\begin{array}{c}\text { FRI } \\
(-)\end{array}$ & $\begin{array}{c}\mathrm{SE} \\
(\mathrm{mJ})\end{array}$ & $\begin{array}{c}\text { Cohesion } \\
(-)\end{array}$ & $\begin{array}{l}\text { Jenike Flow } \\
\text { Index }\left(f f_{c},-\right)\end{array}$ & $\begin{array}{c}\text { Wall Friction } \\
\text { Angle }\left(^{\circ}\right)\end{array}$ \\
\hline $\mathrm{MC} \times \mathrm{RH}$ & NS & NS & NS & NS & NS & NS & NS \\
\hline $\mathrm{MC} \times \mathrm{CP}$ & NS & NS & NS & 0.002 & NS & NS & NS \\
\hline $\mathrm{RH} \times \mathrm{CT}$ & NS & NS & NS & NS & NS & NS & NS \\
\hline $\mathrm{MC} \times \mathrm{CT}$ & NS & NS & NS & NS & NS & 0.04 & NS \\
\hline $\mathrm{MC} \times \mathrm{RH} \times \mathrm{CT}$ & NS & NS & NS & NS & NS & NS & NS \\
\hline $\mathrm{CP} \times \mathrm{CT}$ & NS & NS & NS & $<0.0001$ & NS & 0.01 & NS \\
\hline $\mathrm{RH} \times \mathrm{CP} \times \mathrm{CT}$ & NS & 0.01 & 0.01 & NS & 0.01 & NS & NS \\
\hline $\mathrm{MC} \times \mathrm{CP} \times \mathrm{CT}$ & NS & 0.008 & 0.01 & $<0.0001$ & 0.01 & 0.003 & 0.006 \\
\hline $\mathrm{MC} \times \mathrm{RH} \times \mathrm{CP} \times \mathrm{CT}$ & $<0.0001$ & $<0.0001$ & 0.01 & 0.002 & $<0.0001$ & 0.001 & NS \\
\hline
\end{tabular}

[a] Interactions are considered significant when $\mathrm{p}$-values $<\alpha(0.05)$ and are given in bold font; NS = non-significant interaction.

[b] $\mathrm{MC}=$ moisture content, $\mathrm{RH}=$ relative humidity, $\mathrm{CP}=$ consolidation pressure, and $\mathrm{CT}=$ consolidation time. 
not significantly affected by $\mathrm{CP}$ and $\mathrm{CT}$. Response surface modeling with the most promising flow property variables showed no correlations with CP and CT. Moisture content (\% w.b.) versus BFE showed a clear linear trend (fig. 2), indicating that $\mathrm{MC}$ is an important variable that influences the flowability of low-oil DDGS samples. The dimensionless $\mathrm{MC} / \mathrm{RH}$ ratio was used as the independent variable for further response surface modeling. Plots for other input variable combinations that did not yield any definitive pattern are not shown.

The MC/RH ratio and temperature $\left({ }^{\circ} \mathrm{C}\right)$ were used as independent variables to predict BFE values. Simplified quadratic, power model $\mathrm{C}$, and linear regression models were used to predict $\mathrm{BFE}$ as a function of ( $\mathrm{MC} / \mathrm{RH}$, temperature). Results of RSM and details on parameter estimates are given in table 5. Based on lower standard error values, power model $\mathrm{C}$ most appropriately represented optimum BFE as a function of (MC/RH, temperature), as shown in figure $3 \mathrm{a}$. Additionally, because nonlinear models do not follow the law of sum of squares (i.e., total sum of squares $=$ regression sum of squares + residual sum of squares), $\mathrm{R}^{2}$ is not a valid estimate of model performance for nonlinear models. Standard error is more robust and appropriate for both nonlinear and linear models (Ott and Longnecker, 2000). However, for FRI as a function of (MC/RH, temperature), a linear model with $\mathrm{R}^{2}$ of 0.98 and standard error of 0.11 was the best selected regression model compared to quadratic models (lowest standard error of 0.07 ) because polynomial models, like simple quadratic models, are often complicated and tend to overfit the data. For cohesion as a function of (MC/RH, temperature), power model $\mathrm{D}$ was the optimum model due to its lowest standard error value (0.04). For $f f_{c}$, the linear model showed a reasonable $\mathrm{R}^{2}$ of 0.70 and standard error of 0.61 , and it was chosen over the quadratic model due to its simple structure. Three-dimensional (3D) surface plots of BFE, cohesion, $f f_{c}$, and FRI as a function of (MC/RH, temperature) using power model $\mathrm{C}$, power model $\mathrm{D}$, and a linear regression model, respectively, are presented in figure 3. These models will be useful in predicting the bulk flow characteristics of low-oil DDGS if the environmental and/or handling conditions are known. Although these flow properties depend on many intrinsic characteristics, these models give a quick evaluation of the flow behavior.

\section{Multivariate Analysis of Low-OIL DDGS FLOW BEHAVIOR}

Multivariate analysis is an effective modeling technique when multicollinearity exists among independent variables and dependent variables (Johnson, 1998). Hence, for this study, where we found significant interaction effects between independent variables for low-oil DDGS and significant Pearson correlation coefficients between flow properties (response variables), as seen in table 6, multivariate analysis was appropriate. According to Abdi (2003), when the dependent variables outnumber the independent variables, as in this case (five independent variables and eight flow properties), multivariate analysis is the logical approach to data classification and regression modeling. Therefore, we conducted the multivariate analyses principal component analysis (PCA) and partial least squares (PLS) modeling. The PLS score plot allowed us to classify the entire dataset (including dependent and independent variables) based on only MC levels, as shown in figure 4, while other independent variables (i.e., $\mathrm{RH}$, temperature, $\mathrm{CP}$, and $\mathrm{CT}$ ) did not yield such results. Thus, the classification test results agreed with the previous RSM results in which MC was the most correlated variable for all the flow properties of lowoil DDGS in this study.

Table 5. Prediction RSM regression models for selected flow properties of low-oil DDGS. ${ }^{\text {al }}$

\begin{tabular}{|c|c|c|c|}
\hline Flow Property & Model & Equation & Standard Error \\
\hline \multirow[t]{3}{*}{$\begin{array}{l}\text { BFE } \\
(\mathrm{mJ})\end{array}$} & Power model C & $\begin{array}{c}\boldsymbol{Y}=\boldsymbol{a} \times \boldsymbol{x}_{\mathbf{1}}^{\boldsymbol{b}}+\boldsymbol{c} \times \boldsymbol{x}_{\mathbf{2}}{ }^{\boldsymbol{d}} \\
a=21.10, b=0.30, c=705.94, d=0.04\end{array}$ & 0.11 \\
\hline & Linear $\left(\mathrm{R}^{2}=0.79\right)$ & $\begin{array}{c}Y=a+b \times x_{1}+c \times x_{2} \\
a=674.72, b=0.41, c=133.35\end{array}$ & 2.30 \\
\hline & Simple quadratic & $\begin{array}{c}Y=a+b \times x_{1}+c \times x_{2}+d \times x_{1}^{2}+e \times x_{2}{ }^{2} \\
a=645.59, b=0.89, c=323.24, d=-0.004, e=-419.36\end{array}$ & 1.24 \\
\hline \multirow[t]{3}{*}{$\begin{array}{c}\text { FRI } \\
(-)\end{array}$} & Power model C & $\begin{array}{c}Y=a \times x_{1}^{b}+c \times x_{2}^{d} \\
a=0.05, b=1.035, c=6.43, d=1.08\end{array}$ & 0.11 \\
\hline & Linear $\left(R^{2}=0.98\right)$ & $\begin{array}{c}\boldsymbol{Y}=\boldsymbol{a}+\boldsymbol{b} \times \boldsymbol{x}_{1}+\boldsymbol{c} \times \boldsymbol{x}_{2} \\
a=-0.50, b=0.06, c=7.13\end{array}$ & 0.10 \\
\hline & Simple quadratic & $\begin{array}{c}Y=a+b \times x_{1}+c \times x_{2}+d \times x_{1}{ }^{2}+e \times x_{2}{ }^{2} \\
a=-1.50, b=0.08, c=13.59, d=-0.0002, e=-14.25\end{array}$ & 0.07 \\
\hline \multirow[t]{3}{*}{$\begin{array}{c}\text { Cohesion } \\
(-)\end{array}$} & Power model D & $\begin{array}{c}\boldsymbol{Y}=\boldsymbol{a}+\boldsymbol{x}_{1}{ }^{\boldsymbol{b}} \times \boldsymbol{x}_{\mathbf{2}}{ }^{\mathrm{c}} \\
a=-88, b=0.51, c=0.80\end{array}$ & 0.04 \\
\hline & Linear logarithmic & $\begin{array}{c}Y=a+b \times \ln \left(x_{1}\right)+c \times \ln \left(x_{2}\right) \\
a=0.02, b=0.75, c=1.19\end{array}$ & 0.05 \\
\hline & Simple quadratic & $\begin{array}{c}Y=a+b \times x_{1}+c \times x_{2}+d \times x_{1}{ }^{2}+e \times x_{2}{ }^{2} \\
a=-2.298, b=0.03, c=13.21, d=-0.000203, e=-16.57\end{array}$ & 0.08 \\
\hline \multirow[t]{2}{*}{$\begin{array}{l}\text { Jenike flow index } \\
\left(f f_{c},-\right)\end{array}$} & Linear $\left(R^{2}=0.70\right)$ & $\begin{array}{c}\boldsymbol{Y}=\boldsymbol{a}+\boldsymbol{b} \times \boldsymbol{x}_{1}+\boldsymbol{c} \times \boldsymbol{x}_{2} \\
a=12.51, b=-0.08, c=-24.94\end{array}$ & 0.61 \\
\hline & Simple quadratic & $\begin{array}{c}Y=a+b \times x_{1}+c \times x_{2}+d \times x_{1}^{2}+e \times x_{2}^{2} \\
a=-1.50, b=0.08, c=13.59, d=-0.000169, e=-14.25\end{array}$ & 0.59 \\
\hline \multirow[t]{2}{*}{$\begin{array}{l}\text { Wall friction angle } \\
\left({ }^{\circ}\right)\end{array}$} & Full quadratic & $\begin{array}{c}\boldsymbol{Y}=\boldsymbol{a}+\boldsymbol{b} \times \boldsymbol{x}_{1}+\boldsymbol{c} \times \boldsymbol{x}_{2}+\boldsymbol{d} \times \boldsymbol{x}_{\mathbf{1}}{ }^{2}+\boldsymbol{e} \times \boldsymbol{x}_{2}{ }^{2}+\boldsymbol{f} \times \boldsymbol{x}_{1} \boldsymbol{x}_{2} \\
a=-5.16, b=0.34, c=88.97, d=-0.001, e=-156.40, f=-1.63\end{array}$ & 0.47 \\
\hline & Simplified quadratic & $\begin{array}{c}Y=a+b \times x_{1}+c \times x_{2}+d \times x_{1}^{2}+e \times x_{2}^{2} \\
a=17.48, b=-0.17, c=-55.42, d=0.0009, e=66.57\end{array}$ & 0.52 \\
\hline
\end{tabular}

[a] The best models are indicated by bold type for each flow property; $x_{1}$ and $x_{2}$ are the independent variables temperature $\left({ }^{\circ} \mathrm{C}\right)$ and $\mathrm{MC} / \mathrm{RH}$, respectively, $Y$ is the corresponding flow property, and $a$ to $f$ are the parameter estimates for each model. 


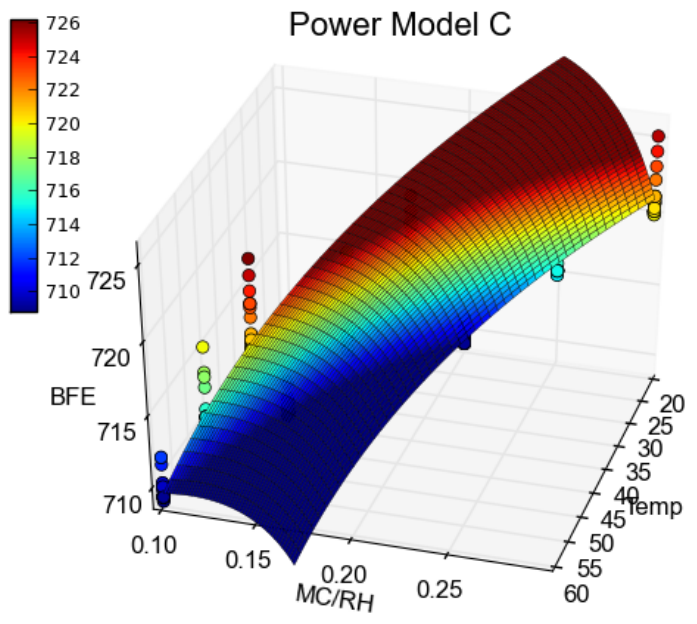

(a)

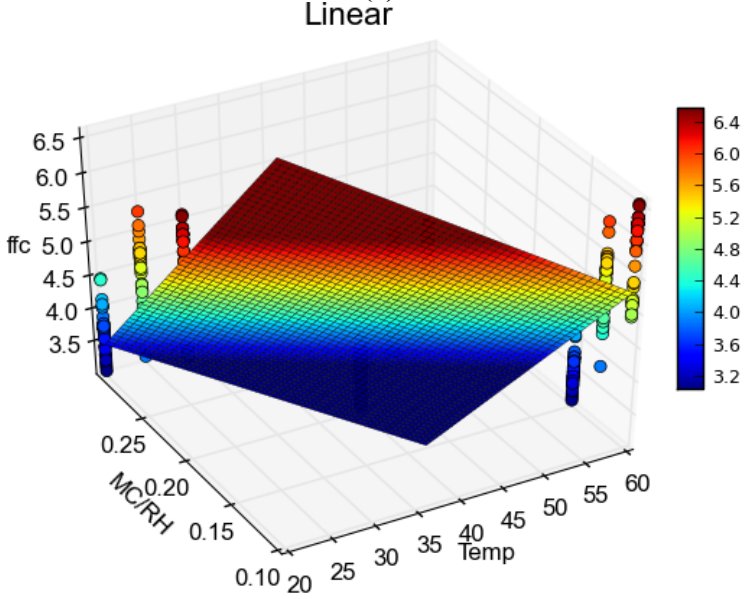

(c)

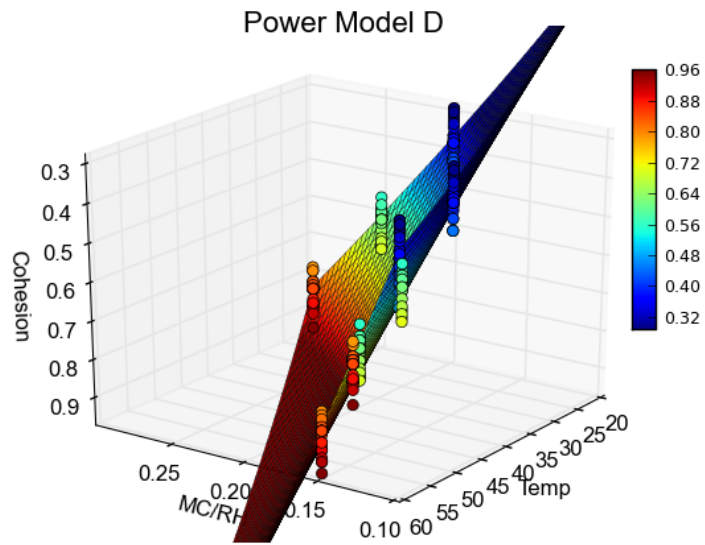

(b)

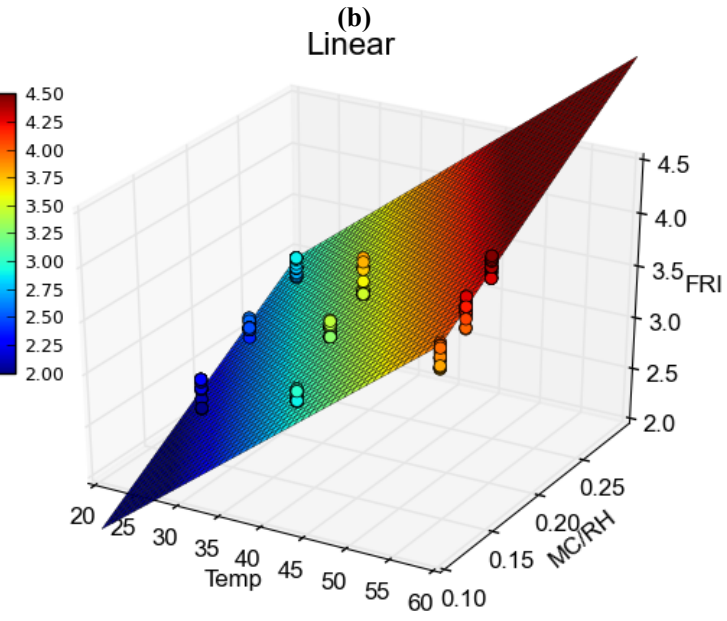

(d)

Figure 3. Response surface plots of (a) BFE, (b) cohesion, (c) $f f_{c}$, and (d) FRI of low-oil DDGS samples.

\section{Principal Component AnAlysis (PCA)} OF LOW-OIL DDGS FLOW BEHAVIOR

Using the covariance matrix method, PCA showed that two components were sufficient to represent maximum variability in the entire dataset without significant loss of information (Johnson, 1998). This also evident in figure 5a, where the maximum difference in eigenvalues was observed after the first two principal components, indicating that just two principal components were sufficient to transform the entire multivariable dataset. PCA also yielded loading plots with the most influential variables in the entire dataset. In figures $5 \mathrm{~b}$ and $5 \mathrm{c}$, the loading values and the length of the lines parallel to the $x$-axis or $y$-axis indicate the degree of influence of the independent variables. Figure $5 \mathrm{~b}$ shows that the most influential independent variables were MC (\% w.b.), RH (\%), and temperature $\left({ }^{\circ} \mathrm{C}\right)$, with PCA scores of $1.0,0.75$, and 0.76 , respectively. These results support the RSM results in which $\mathrm{MC}, \mathrm{RH}$, and temperature were selected as key independent variables to model all flow properties. Furthermore, these results prove that environmental conditions play a major role in influencing the bulk flow characteristics of low-oil DDGS. With flow (dependent) variables, the PCA loading plot showed BFE (loading score of 0.98 ) and wall friction angle (loading score of -1.0) as the most influential flow properties (fig. 5c). BFE and wall friction angle had the highest influence with loading scores above 0.98; for SE, cohesion, FRI, and SI, the degree of influence was below 0.90 . A loading score above 0.90 is typically needed to conclude a significant degree of influence from independent variables. BFE also yielded favorable RSM results, with a low standard error of 0.11 with power model $\mathrm{C}$ (table 5), indicating that the PCA and RSM results agree with each other.

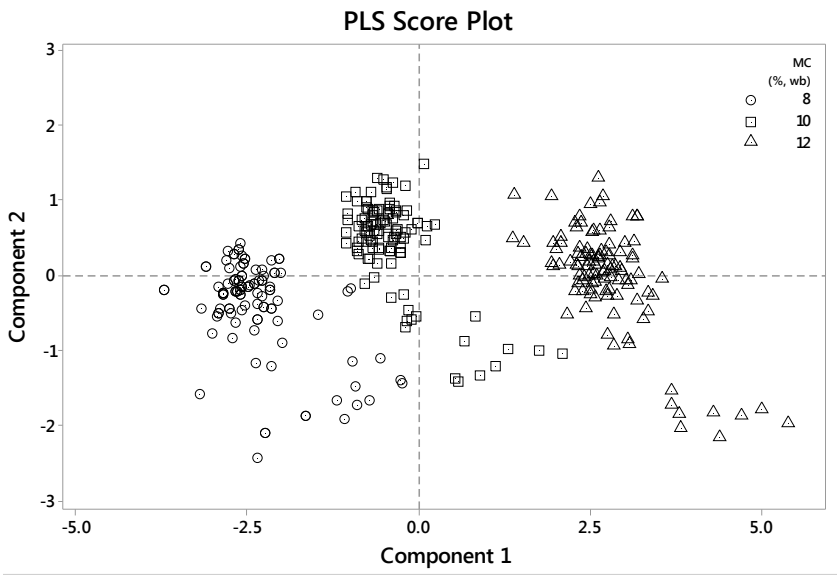

Figure 4. PLS score plot classified based on independent variables. 
Table 6. Pearson correlation coefficients $(p<0.05)$ between flow properties of low-oil DDGS samples. ${ }^{[a]}$

\begin{tabular}{cccc}
\hline Flow Property Relationship & $\mathrm{r}$ & $\mathrm{R}^{2}$ & $\mathrm{p}$-Value \\
\hline BFE $\times$ SI & 0.897 & 0.805 & $<0.0001$ \\
FRI $\times$ SI & 0.767 & 0.588 & $<0.0001$ \\
SE $\times$ SI & 0.653 & 0.426 & $<0.0001$ \\
Cohesion $\times$ SI & 0.892 & 0.796 & $<0.0001$ \\
$f f_{c} \times$ SI & -0.840 & 0.706 & $<0.0001$ \\
Cohesion $\times$ SE & 0.612 & 0.375 & $<0.0001$ \\
$f f_{c} \times$ SE & -0.577 & 0.333 & $<0.0001$ \\
BFE $\times$ FRI & 0.777 & 0.604 & $<0.0001$ \\
BFE $\times$ SE & 0.683 & 0.466 & $<0.0001$ \\
BFE $\times$ Cohesion & 0.968 & 0.937 & $<0.0001$ \\
FRI $\times$ SE & 0.526 & 0.277 & $<0.0001$ \\
FRI $\times$ Cohesion & 0.777 & 0.604 & $<0.0001$ \\
$f f_{c} \times$ FRI & -0.747 & 0.558 & $<0.0001$ \\
$f f_{c} \times$ Cohesion & -0.866 & 0.750 & $<0.0001$ \\
\hline BFE $=$ basic flow energy, SI $=$ stability index, FRI $=$ flow rate index, \\
$\mathrm{SE}=$ specific energy, CBE $=$ conditioned bulk density, and $f f_{c}=$ Jenike \\
flow function.
\end{tabular}

\section{Partial Least SQuares (PLS) Regression}

MODELING OF LOW-OIL DDGS FLOW BEHAVIOR

PLS modeling reduces the predictors (independent variables) to a much smaller set of uncorrelated components (smaller in comparison to the original set of independent variables) and performs least squares regression on the new components instead of the original dataset. PLS modeling is highly useful where there is sufficient collinearity between more than two predictors. The low-oil DDGS flow properties data contained significant amounts of interaction effects between predictors, as shown in table 4. In the PLS regression modeling, flow properties (SI, BFE, FRI, cohesion, and $f f_{c}$ ) were modeled as a function of $\mathrm{MC}$, temperature, $\mathrm{RH}, \mathrm{CP}$, and CT using two principal components. The results from the PLS regression yielded $\mathrm{R}^{2}$ values between 0.62 and 0.97 for all flow properties (table 7). Cohesion (0.97) and BFE (0.94) yielded $\mathrm{R}^{2}$ values greater than 0.9 with only two principal components. The corresponding PLS model parameter estimates and detailed statistics are given in table 7. With high $\mathrm{R}^{2}$ values, the data in table 7 confirm that two principal components are optimum to predict flow properties as a function of the independent variables used in this study. The goodness of fit of the PLS regression models was checked with a cross-validation method in which the $i$ th observation

Table 7. Parameter estimates from PLS regression modeling for selected response variables as a multivariate function of all independent variables for low-oil DDGS samples. ${ }^{\text {[a] }}$

\begin{tabular}{cccccc}
\hline \multicolumn{2}{c}{$\begin{array}{c}\text { SI } \\
(-)\end{array}$} & $\begin{array}{c}\text { BFE } \\
(\mathrm{mJ})\end{array}$ & $\begin{array}{c}\text { FRI } \\
(-)\end{array}$ & $\begin{array}{c}\text { Cohesion } \\
(-)\end{array}$ & $\begin{array}{c}f f_{c} \\
(-)\end{array}$ \\
\hline Parameter estimates $^{[\mathrm{b}]}$ & & & & & \\
Constant & 1.1360 & 684.440 & 1.857 & -0.651 & 10.4139 \\
MC & 0.0170 & 2.8880 & 0.074 & 0.1220 & -0.5143 \\
Temperature & -0.00005 & 0.0030 & -0.00001 & 0.000055 & -0.0002 \\
RH & -0.00005 & 0.0030 & -0.00001 & 0.000055 & -0.0002 \\
CP & 0.0029 & 0.0500 & 0.00077 & 0.00134 & 0.0064 \\
CT & 0.001 & 0.2550 & 0.00626 & 0.0055 & -0.0350 \\
\hline Model statistics & & & & & \\
F statistic & 695.91 & 2325.03 & 262.82 & 5636.29 & 550.81 \\
$\mathrm{R}^{2}$ & 0.811 & 0.94 & 0.62 & 0.97 & 0.77 \\
PLS components & 2 & 2 & 2 & 2 & 2 \\
\hline
\end{tabular}

[a] Interactions are considered significant when $\mathrm{p}$-values $<\alpha(0.05)$; $\mathrm{SI}=$ stability index, $\mathrm{BFE}=$ basic flow energy, $\mathrm{FRI}=$ flow rate index, and $f f_{c}=$ Jenike flow index.

[b] $\mathrm{MC}=$ moisture content, $\mathrm{RH}=$ relative humidity, $\mathrm{CP}=$ consolidation pressure, and $\mathrm{CT}=$ consolidation time.

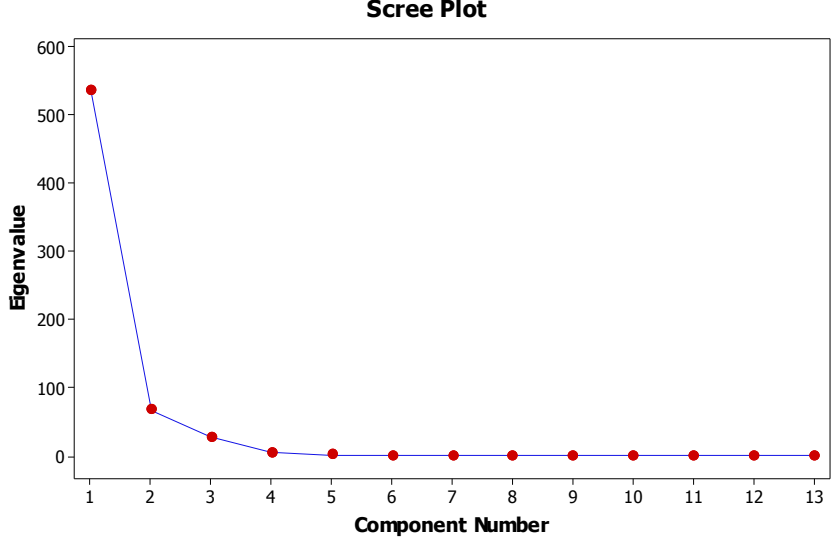

(a)

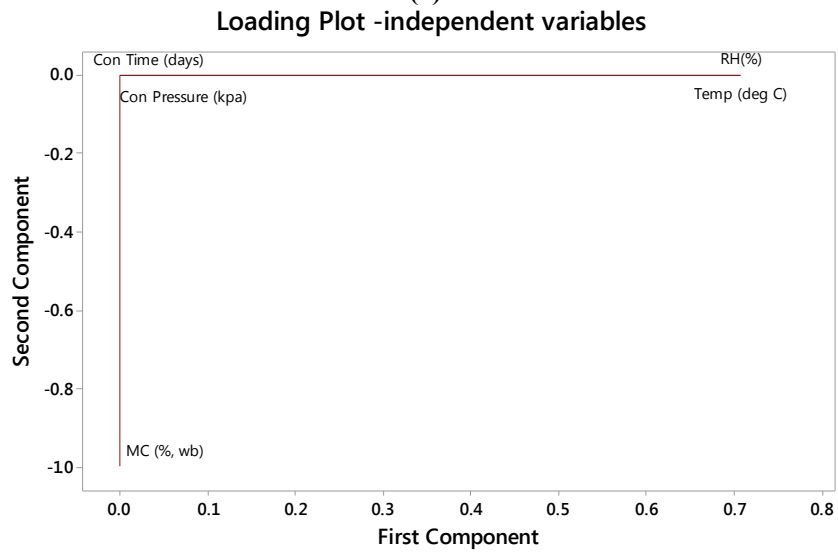

(b)

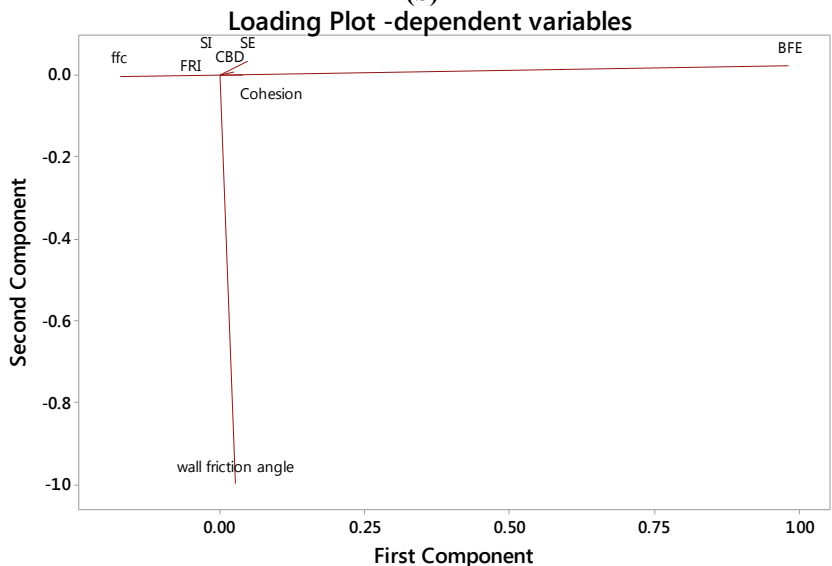

(c)

Figure 5. PCA results: (a) scree plot showing requirement of two components to summarize the low-oil DDGS dataset, (b) loading plots with influencing independent variables, and (c) loading plots with influencing flow properties.

was deleted and the PLS model was developed from rest of the dataset $(n-i)$ (Srivastava, 2002). Loading plot results of PLS regression modeling confirmed that $\mathrm{MC}$, temperature, and $\mathrm{RH}$ are the most influential independent variables that influence SI, BFE, FRI, cohesion, and Jenike flow index. The $\mathrm{R}^{2}$ values for linear models from the RSM technique ranged from 0.70 to 0.98 (table 5), similar to the $R^{2}$ range of 0.77 to 0.98 for PLS modeling for SI, BFE, cohesion, and $f f_{c}$ in table 7. However, unlike 3D RSM, PLS modeling has the ability to incorporate multiple independent variables in order to develop a regression model for a single response variable. 
Therefore, for both the dynamic and shear flow properties, the environmental variables have a more significant effect than the handling or storage conditions, such as consolidation pressure or consolidation time. However, if low-oil DDGS is stored longer than the period tested in this study, there could be higher cohesion between particles due to consolidation.

\section{CONCLUSIONS}

This study considered the effects of consolidation pressure and consolidation time, varying storage temperature, and relative humidity on the flow properties of low-oil DDGS. The key results obtained from the study are:

- Higher values of BFE and cohesion at elevated moisture content indicated potential caking and flow problems in low-oil DDGS.

- The MC, RH, and temperature variables showed significant influences on the flow properties of low-oil DDGS.

- In RSM modeling, BFE and cohesion $=f$ (temperature, $\mathrm{MC} / \mathrm{RH}$ ) yielded predictive nonlinear models with standard error values around 0.04, and FRI and Jenike flow index $=f($ temperature, $\mathrm{MC} / \mathrm{RH})$ yielded predictive linear models with $\mathrm{R}^{2}>0.82$ and standard error around 0.10. These two models will help predict BFE and cohesion values with known temperature, $\mathrm{MC}$, and $\mathrm{RH}$ values.

- In PLS modeling, flow properties such as SI, BFE, and cohesion $=f(\mathrm{MC}$, temperature, $\mathrm{RH}, \mathrm{CP}$, and $\mathrm{CT})$ yielded useful predictive models $\left(\mathrm{R}^{2}>0.80\right)$ with only two principal components.

- Multivariate PCA revealed that MC, RH, and temperature were the most significant variables in modeling the flow property dataset, but there was no trend with $\mathrm{CP}$ and CT within the selected ranges of $\mathrm{CP}(0,3.44$, and $6.89 \mathrm{kPa}$ ) and CT (2 to 8 days).

- In both RSM and PLS modeling, BFE and cohesion were the favorable flow variables that yielded successful regression models with the given ranges of independent variables. Thus, for practical purposes, these dynamic flow variables are preferred to predict flow issues without investing in additional flow properties.

These observations and models will vitally help the quantification and prediction of flow behavior of low-oil DDGS during handling and transportation.

\section{REFERENCES}

Abdi, H. (2003). Partial least square regression (PLS) regression. In M. Lewis-Beck, A. Bryman, \& T. Futing (Eds.), Encyclopedia of social sciences research methods. Thousand Oaks, CA: Sage.

ASABE. (2009). S319.4: Method of determining and expressing fineness of feed materials by sieving. St. Joseph, MI: ASABE.

ASTM. (1993). D6393: Standard test method for bulk solids characterization by Carr indices. West Conshohocken, PA: ASTM.

Bhadra, R., Muthukumarappan, K., \& Rosentrater, K. A. (2009). Flowability properties of commercial distillers dried grains with solubles (DDGS). Cereal Chem. J., 86(2), 170-180.
http://dx.doi.org/10.1094/CCHEM-86-2-0170

Bhadra, R., Muthukumarappan, K., \& Rosentrater, K. A. (2013). Effects of varying CDS levels and drying and cooling temperatures on flowability properties of DDGS. Cereal Chem. J., 90(1), 35-46. http://dx.doi.org/10.1094/CCHEM-04-12-0042-R

Bian, Q., Sittipod, S., Garg, A., \& Ambrose, R. P. K. (2015). Bulk flow properties of hard and soft wheat flours. J. Cereal Sci., 63, 88-94. http://dx.doi.org/10.1016/j.jcs.2015.03.010

Carr Jr., R. L. (1965). Evaluating flow properties of solids. Chem. Eng., 72(3), 163-168.

Freeman, R. (2007a). Measuring the flow properties of consolidated, conditioned and aerated powders: A comparative study using a powder rheometer and a rotational shear cell. Powder Tech., 174(1-2), 25-33. http://dx.doi.org/10.1016/j.powtec.2006.10.016

Freeman. (2007b). FT4 powder rheometer: Variable flow rate method. Tewkesbury, UK: Freeman Technology.

Freeman. (2008). FT4 powder rheometer: Specific energy. Tewkesbury, UK: Freeman Technology.

Freeman, R. (2011). Assessing powder stability. Tewkesbury, UK: Freeman Technology. Retrieved from http://www.freemantech.co.uk/ literature/

Ganesan, V., Rosentrater, K. A., \& Muthukumarappan, K. (2007). Modeling flow properties of regular and reduced-fat distillers dried grains with solubles (DDGS). Food Bioproc. Tech., 187(2), 130-137.

Ganesan, V., Rosentrater, K. A., \& Muthukumarappan, K. (2009). Physical and flow properties of regular and reduced-fat distillers dried grains with solubles (DDGS). Food Bioproc. Tech., 2(2), 156-166. http://dx.doi.org/10.1007/s11947-007-0026-x

Jenike, A. W. (1964). Storage and flow of solids. Bulletin No. 123. Salt Lake City, UT: University of Utah, Utah Engineering Station.

Jessen, H. (2013). Corn oil extraction examined from several angles during webinar. Ethanol Producer Magazine (15 Nov. 2013). Grand Forks, ND: BBI International. Retrieved from $\mathrm{http}$ //ethanolproducer.com/articles/10475/corn-oil-extractionexamined-from-several-angles-during-webinar

Johnson, D. E. (1998). Applied multivariate methods for data analysis (1st ed.). Pacific Grove, CA: Brooks/Cole.

Kingsly, A. R. P., Ileleji, K. E., Clementson, C. L., Garcia, A., Maier, D. E., Stroshine, R. L., \& Radcliff, S. (2010). The effect of process variables during drying on the physical and chemical characteristics of corn dried distillers grains with solubles (DDGS): Plant-scale experiments. Bioresour. Tech., 101(1), 193-199. http://dx.doi.org/10.1016/j.biortech.2009.07.070

Knowlton, T. M., Klinzing, G. E., Yang, W. C., \& Carson, J. W. (1994). The importance of storage, transfer, and collection. Chem. Eng. Prog., 90(4), 44-54.

Leturia, M., Benali, M., Lagarde, S., Ronga, I., \& Saleh, K. (2014). Characterization of flow properties of cohesive powders: A comparative study of traditional and new testing methods. Powder Tech., 253, 406-423. http://dx.doi.org/10.1016/j.powtec.2013.11.045

McNeill, S. G., Montross, M. D., Thompson, S. A., Ross, I. J., \& Bridges, T. C. (2008). Packing factors of feed products in storage structures. Appl. Eng. Agric., 24(5), 625-630. http://dx.doi.org/10.13031/2013.25260

Ott, L., \& Longnecker, M. (2000). An introduction to statistical methods and data analysis (5th ed.). Pacific Grove, CA: Duxbury Press.

Shurson, J., \& Kerr., B. (2012). Reduced-oil DDGS: It's not the fat, it's the fiber. Presented at the 2012 NutriQuest DDGS Symposium. Mason City, IA: NutriQuest.

Spiehs, M. J., Whitney, M. H., \& Shurson, G. C. (2002). Nutrient database for distiller's dried grains with solubles produced from 
new ethanol plants in Minnesota and South Dakota. J. Animal Sci., 80(10), 2639-2645.

http://dx.doi.org/10.2527/2002.80102639x

Srivastava. M., S. (2002). Methods of multivariate statistics (1st ed.). Hoboken, NJ: John Wiley \& Sons.

Teunou, E., \& Fitzpatrick, J. J. (2000). Effect of storage time and consolidation on food powder flowability. J. Food Eng., 43(2), 97-101. http://dx.doi.org/10.1016/S0260-8774(99)00137-5 